\title{
Etika Jurnalistik, Perempuan dan Pemberitaan Pelecehan Seksual di Media Online
}

\author{
Kadek Kiki Astria ${ }^{1}$, Ahmad Khairul Nuzuli ${ }^{2}$, Fitri Handayani ${ }^{3}$ \\ ${ }^{1}$ Fakultas Ekonomi dan Sosial, Universitas Amikom Yogyakarta \\ ${ }^{2,3}$ Instutut Agama Islam Negeri Kerinci \\ kikiastria@amikom.ac.id
}

\begin{abstract}
This study discusses the reporting of Sexual Harassment in the online media Tribunnews.com from the standpoint of journalistic ethics and sexual harassment. Media reporting is demanded to be gender responsive, but media content cannot be separated from market interests. The method used in this research is ethnographic content analysis. The results show that some of the publications on Tribunnews.com have met Article 5 Journalistic Code of Ethics, but there are some that have not been gender responsive, which tends to display the workplace address, place of study and residence of victims of immoral crime.
\end{abstract}

Keyword: Journalistic Code of Ethics, Women, Preaching, Sexual Harassment

Abstrak. Studi ini membahas tentang pemberitaan Pelecehan Seksual di media online Tribunnews.com dari sudut pandang etika jurnalistik dan pelecehan seksual. Pemberitaan media dituntut untuk bisa responsif secara gender, namun isi media tidak terlepas kepentingan pasar. Metode yang digunakan dalam penelitian ini adalah analisis isi etnografi. Hasil menunjukkan bahwa beberapa pemberitan di Tribunnews.com sudah memenuhi Kode Etik Jurnalistik Pasal 5, namun ada beberapa belum responsif gender, yang cenderung menampilkan alamat tempat kerja, tempat kuliah dan tempat tinggal korban kejahatan asusila.

Kata Kunci: Kode Etik Jurnalistik, Perempuan, Pemberitaan, Pelecehan Seksual.

\section{PENDAHULUAN}

Di era globalisasi ini, terdapat kecenderungan masyarakat dalam mengakses berita secara online. Menurut hasil riset Asosiasi Penyelenggara Jasa Internet Indonesia (APJII) pada tahun 2019, dari total penduduk Indonesia 264 juta jiwa, sebanyak 171, 7 Juta Jiwa atau sekitar 64,8\% telah terhubung dengan koneksi internet (Wahyudiyono, 2019). Riset ini juga sejalan dengan budaya membaca media yang beralih ke media online yang berbasis digital, yang dikenal lebih praktis dan mobile (Ghofur \& Rachma, 2019).

Tribunnews.com merupakan salah satu situs media online anak perusahaan Kompas. Menurut data dari dari situs pemeringatan website dunia, Alexa.com, Tribunnews.com merupakan situs berita nomor satu di Indonesia. 
Hal ini menujukkan bahwa Tribunnews.com merupakan salah satu rujukan utama masyarakat Indonesia dalam mengkonsumsi media online (Nuzuli et al., 2021).

\section{Tabel 1. Website Portal Berita Terpopuler Di Indonesia tahun 2019 Versi Alexa.com}

\begin{tabular}{cc}
\hline Nama Portal Berita & Nilai \\
\hline Tribunnews.com & Rank in Indonesia : 3 \\
\hline Detik.com & Rank in Indonesia : 5 \\
\hline Liputan6.com & Rank in Indonesia : 6 \\
\hline Sindonews.com & Rank in Indonesia : 7 \\
\hline
\end{tabular}

(sumber : http://www.alexa.com/topsites/countries/Id)

Isu seksual dan kekerasan seksual merupakan topik berita yang mempunyai nilai jual tinggi bagi media online (Nuzuli, 2021). Adapun tema kekerasan seksual yang paling banyak diliput oleh media adalah yakni pemerkosaan, pelecehan seksual, dan penjualan perempuan (Rossy \& Wahid, 2015). Selain itu, media online era sekarang ini juga menampilkan upaya normalisasi kekerasan seksual dalam konten pemberitaannya, dengan menyudutkan dan menyalahkan perempuan sebagai korban, sehingga kekerasan seksual pada perempuan dianggap sebagai sesuatu yang wajar (Indainanto, 2020).

Fokus pemberitaan di media online pun juga mulai beralih ke isu kekerasan seksual, tujuannya tidak lain adalah tekanan ekonomi. Fokus ini terlihat dari porsi pemberitaan kekerasaan seksual yang lebih banyak dari pemberitaan tema lain (Aristi et al., 2021). Hal ini dikarenakan media sudah tidak lagi netral, karena ada kepentingan ekonomi yang dianggap lebih penting sebagai efek industrialisasi media massa sebagai agen ekonomi (Arnus, 2014). Industrialisasi media membuat fungsi media massa menjadi penyampai informasi kepada masyarakat menjadi bergeser karena adanya kepentingan memperoleh laba yang sebesar-besarnya (Handoyo, 2016).

Salah pedoman wartawan dalam meliput berita pelecehan seksual adalah Pasal 5 Kode Etik Jurnalistik yang menyatakan bahwa "Wartawan Indonesia tidak menyebutkan dan menyiarkan identitas korban identitas korban kejahatan susila". Dalam hal ini identitas yang dimaksud adalah hal yang memudahkan orang untuk melacak data diri korban misalnya nama korban, 
nama orang tua, alamat rumah/tempat, alamat sekolah, alamat kantor. Etika Jurnalistik merupakan panduan kerja jurnalis yang sangat penting untuk diterapkan, baik secara etik, prinsip maupun aturan (Choliq, 1970).

Namun pada dasarnya begitu banyak wartawan yang dibekali kompetensi yang cukup dalam menyajikan pemberitaan yang responsif gender. akibatnya Dewan Pers menerbitkan Seruan Dewan Pers No 189 Tahun 2013 terkait dengan pemberitaan kejahatan susila dan menekankan lagi Pasal Pasal 5 Kode Etik Jurnalistik di atas. Dalam seruan ini Dewan Pers meminta para wartawan agar lebih serius dalam melindungi korban kejahatan susila yang umum korbannya adalah perempuan dan anak. Tujuan serutan ini adalah untuk menghindari korban mengalami kejahatan lagi, dan memperkecil dampak trauma yang dialami korban (AJI, 2015).

Penyajian berita akan mempengaruhi cara pandang masyarakat melihat isu perempuan dan pelecehan seksual. Tujuan penelitian ini adalah untuk melihat bagaimana gambaran implementasi kode etik media mengenai pemberitaan tentang perempuan dan pelecehan seksual.

Penelitian ini menggunakan metode deskriptif kuantitatif, dengan tujuan memberi deskripsi realitas yang ada di lapangan atau objek penelitian (Sugiyono, 2018) Teknik pengumpulan data pada penelitian ini adalah menggunakan teknik pengumpulan data berupa dokumentasi (Nuzuli et al., 2021). Adapun dokumentasi yang dimaksud dalam penelitian ini adalah teks pemberitaan Tribunnews.com mengenai pelecehan seksual yang melibatkan perempuan sebagai korban selama bulan Juli-Juli 2019. Beradasarkan situs Alexa.com, Tribunnews.com merupakan situs berita online nomor satu di Indonesia. 3,57 juta pengunjung per hari dengan keunggulan Daily Time on Site.

Terdapat 16 berita pemberitaan Tribunnews.com mengenai pelecehan seksual yang melibatkan perempuan sebagai korban selama bulan Juni-Juli 2019.

Tabel 2. Pemberitaan pelecehan seksual yang melibatkan perempuan sebagai korban selama bulan Juni-Juli 2019 di Tribunnews.com

\begin{tabular}{|lll|}
\hline No & Tanggal & Judul Berita \\
\hline 1. & 13 Juni 2019 & $\begin{array}{l}\text { Polisi Amankan Oknum Guru Ngaii yang Diduga } \\
\text { Cabuli Murid-muridnya }\end{array}$ \\
\hline
\end{tabular}




\begin{tabular}{|c|c|c|}
\hline 2. & 14 Juni 2019 & $\begin{array}{l}\text { Wanita Usia } 40 \text { Tahun Jadi Korban Pelecehan } \\
\text { Dalam Kolam di Guci Tegal, Pelakunya Bocah } 16 \\
\text { Tahun }\end{array}$ \\
\hline 3. & 17 Juni 2019 & $\begin{array}{l}\text { Pengakuan Oknum Bidan Desa yang 'Video Call' } \\
\text { dengan Pacarnya Tanpa Busana }\end{array}$ \\
\hline 4. & 17 Juni 2019 & $\begin{array}{l}\text { Ikut Pelatihan, Gadis Penyandang Disabilitas Jadi } \\
\text { Korban Pelecehan Seksual Oknum di Dinsos }\end{array}$ \\
\hline 5. & 17 Juni 2019 & $\begin{array}{l}\text { Gadis Penyandang Disabilitas Korban Pelecehan } \\
\text { Seksual Ternyata Korban Selamat Tsunami Aceh }\end{array}$ \\
\hline 6. & 3 Juli 2019 & $\begin{array}{l}\text { Oknum ASN Jadi tersangka Pelecehan Gadis } \\
\text { Disabilitas }\end{array}$ \\
\hline 7. & 5 Juli 2019 & $\begin{array}{l}\text { Dilaporkan Lakukan Pelecehan Seks Terhadap } \\
\text { Stafnya, Kepala Terminal Tingkir Salatiga Dicopot }\end{array}$ \\
\hline 8. & 9 Juli 2019 & $\begin{array}{l}\text { Kasus Pelecehan ABG } 13 \text { Tahun Terungkap } \\
\text { Setelah Korbannya Kerap Mengunci Diri di } \\
\text { Kamar }\end{array}$ \\
\hline 9. & 11 Juli 2019 & $\begin{array}{l}15 \text { Santri di Lhokseumawe Diduga Jadi Korban } \\
\text { Pelecehan Oleh Pemimpin Ponpes }\end{array}$ \\
\hline 10. & 11 Juli 2019 & $\begin{array}{l}\text { Dipaksa Layani Teman Ibunya dan Dicekoki Sabu, } \\
\text { Remaja Asal Depok Depresi: Hancur Masa Depan } \\
\text { Saya }\end{array}$ \\
\hline 11. & 12 Juli 2019 & $\begin{array}{l}\text { Oknum Guru Agama Nodai Santrinya di Belakang } \\
\text { Rumah }\end{array}$ \\
\hline 12. & 13 Juli 2019 & $\begin{array}{l}\text { Dugaan Pelecehan Seksual di Pesantren Berbuntut } \\
\text { Panjang, Wali Santri Minta Uang Muka } \\
\text { Dikembalikan }\end{array}$ \\
\hline 13. & 14 Juli 2019 & $\begin{array}{l}\text { Pimpinan Pesantren Tersangka Kasus Dugaan } \\
\text { Pelecehan Seksual Minta Penangguhan Penahanan }\end{array}$ \\
\hline 14. & 16 Juli 2019 & $\begin{array}{l}\text { Enam Kasus Pencabulan yang Membuat Geger } \\
\text { Kabupaten Bolsel dalam } 7 \text { Bulan Terakhir }\end{array}$ \\
\hline 15. & 17 Juli 2019 & $\begin{array}{l}\text { Terjadi } 2 \text { Kali Kasus Pelecehan Seksual di } \\
\text { Yogyakarta dengan Korban Wisatawan dalam } \\
\text { Waktu Sebulan }\end{array}$ \\
\hline 16. & 18 Juli 2019 & $\begin{array}{l}\text { Kasus Dugaan Pelecehan Seksual, Saat } \\
\text { Kumpulkan Tugas Ini yang Dilakukan Oknum } \\
\text { Dosen di Ruangannya }\end{array}$ \\
\hline
\end{tabular}


Fokus penelitian ini adalah menganalisis teks berita mengenai pelecehan seksual yang melibatkan perempuan sebagai korban. Teks berita ini dihubungkan dengan Kode Etik Jurnalistik Pasal 5 yang berbunyi "Wartawan Indonesia tidak menyebutkan dan menyiarkan identitas korban identitas korban kejahatan susila". Terdapat tiga alur utama dalam analisis penelitian ini, yakni : reduksi data, penyajian data, dan penarikan kesimpulan penelitian (Berg dan Lune, 2012)

\section{HASIL DAN PEMBAHASAN}

Pada Tabel 2 tentang pemberitaan pelecehan seksual di atas, berita 2,3,4,5,6,8.9,10,12,13,14,15, dan 16 menunjukkan bahwa tidak ditemukan pelanggaran. Pada berita 1 dengan judul "Polisi Amankan Oknum Guru Ngaji yang Diduga Cabuli Murid-muridnya" memiliki indikasi memaparkan alamat dari korban. Hal ini bisa terlihat dari penyajian teks berikut:

“AN (50), seorang guru ngaji di Desa Panusupan, Kecamatan Cilongok, Kabupaten Banyumas, Jawa Tengah melakukan pelecehan seksual kepada para muridnya”. (JTI,2019)

Berita 1 seharusnya tidak menyajikan alamat secara lengkap, karena Desa alamat tersangka juga merupakan alamat bagi para korban. Seharusnya alamatnya tidak disajikan lengkap dengan nama desa, melainkan bisa disajikan hanya sebatas Kecamatan dan Kota/Kabupaten. Selain itu, Pada berita 7 dengan judul "Dilaporkan Lakukan Pelecehan Seks Terhadap Stafnya, Kepala Terminal Tingkir Salatiga Dicopot" memiliki indikasi memberitakan identitas korban berupa alamat tempat korban bekerja.

"Kepala Terminal Tipe A Tingkir Kota Salatiga Suharno membantah adanya informasi dugaan percobaan pemerkosaan terhadap stafnya ketika jam kerja (RIS, 2019)"

Terminal Tipe A Tingkir Kota Salatiga merupakan tempat korban bekerja. Informasi ini akan mempermudah orang untuk melacak korban. Sebaiknya penyajiannya hanya sebatas mengatakan Kepala sebuah terminal di Kota Salatiga. Karena, jika memaparkan alamat detail institusi tempat korban bekerja akan mempermudah pelacakan identitas korban. Hal yang sama juga terlihat di pemberitaan 11 dengan judul "Oknum Guru Agama Nodai Santrinya di Belakang Rumah" :

"Kelakukan Mohammad Amri (32) warga Dusun Kandangan, Desa Kepuh Kembeng, Kecamatan Peterongan, Kabupaten Jombang, tak pantas ditiru. 
Dia tega merenggut kegadisan seorang mahasiswi, yang tak lain tetangganya sendiri" (Sriwahyunik, 2019)

Walaupun dalam teks ini tidak dikatakan langsung alamat korban, melainkan alamat pelaku. Namun penjelasan bahwa korban adalah tetangga pelaku sudah merupakan informasi yang memberikan gambaran alamat korban.

Berita 16 tentang "Kasus Dugaan Pelecehan Seksual, Saat Kumpulkan Tugas Ini yang Dilakukan Oknum Dosen di Ruangannya" dengan kalimat :

"Oknum dosen UIN Raden Intan tersebut kini harus menjalani sidang di Pengadilan Negeri (PN) Tanjungkarang, pada Selasa 23 Juli 2019”. (Hanif Mustafa, 2019)

"Tak lama setelah muncul informasi oknum dosen diduga cabul, sebagai bentuk solidaritas terhadap korban, sejumlah mahasiswa UIN Raden Intan menggelar aksi demonstrasi di depan gedung Dekanat Fakultas Ushuluddin”, (Hanif Mustafa, 2019)

Kalimat ini mengindikasikan bahwa barita ini telah menyajikan alamat tempat korban mengenyam pendidikan berupa nama fakultas, universitas, hingga kota.

Pemberitaan 1,7, 11 dan 16 ini sudah melanggar Pasal 5 Kode Etik Jurnalistik. Dalam pasal ini ada larangan bagi wartawan untuk menyajikan identitas korban kejahatan susila. Hal ini identitas yang dimaksud adalah hal yang memudahkan orang untuk melacak data diri korban misalnya nama korban, nama orang tua, alamat rumah/tempat, alamat sekolah, alamat kantor.

Media online merupakan salah satu bentuk media massa modern yang mengutamakan kecepatan dalam menyampaikan informasi/berita kepada masyarakat banyak. Zaman sekarang ini informasi sudah menjadi salah satu kebutuhan utama manusia dalam mengobati kecemasan (Gaio, 2015).

Dalam pembuatan berita terdapat kode etik yang harus dipatuhi oleh wartawan dan awak media. Kode etik dibuat bukan masalah salah dan benar, tetapi bagaimana cara wartawan beretika dalam memberikan informasi kepada publik. Ada beberapa jenis berita, salah satu berita yang paling laku di dalam masyarakat sekarang ini adalah berita seks dan kekerasan (Aristi et al., 2021). 
Tribunnews.com sendiri merupakan salah satu media online yang populer di Indonesia. Sebagai media besar sudah seharusnya Tribunnews.com menerapkan Kode Etik Jurnalistiknya ke dalam produknya.

Walaupun dalam proses peliputan, pengeditan hingga pendistribusian berita media online dibebaskan. Namun sebagai bentuk tanggung jawab sosial Kode Etik Jurnalistik dibuat untuk memenuhi standar pemberitaan yang bertanggung jawab dan profesional. Hal ini sejalan dengan pendapatnya Masduki (2004) wartawan mempunyai kewajiban untuk memenuhi Kode Etik Jurnalistik dan norma-norma yang berlaku di masyarakat.

Secara umum, Pemberitaan Tribunnews.com pada bulan Juni hingga Juli 2019 sebagian besar telah memenuhi kode etik Pasal 5 tentang "Wartawan Indonesia tidak menyebutkan dan menyiarkan identitas korban identitas korban kejabatan susila". Hal ini bisa terlihat dari 16 berita pada bulan Juni hingga Juli 2019, 12 Berita sudah memenuhi Kode Etik Jurnalistik Pasal 5.

Namun 4 Berita lainnya masih terindikasi memberitahukan kepada publik mengenai identitas pelaku yang berupa tempat kerja, tempat kuliah dan tempat tinggal korban, sehingga ini akan memudahkan pelaku dalam melacak korban.

Melampirkan alamat akan membuat korban menjadi terekspos dan disorot sehingga media menjadi mengulit identitas korban. Hal ini berpotensi membuat potensi trauma bagi korban dan keluarga korban. Hal ini akan berimbas pada tekanan batin dan traumatis berulang kali pada korban.

\section{KESIMPULAN}

Walaupun Tribunnews.com konsisten dalam upaya menerapkan Pasal 5 Kode Etik Jurnalistik. Namun Kenyataan beberapa berita masih mengindikasikan bahwa melanggar pasal tersebut. Dari 16 Berita yang menjadi objek penelitian ini 12 Berita sudah ada upaya untuk melindungi identitas perempuan korban kejahatan asusila. Namun, empat berita lainnya masih memberikan teks berita yang mengarahkan kepada memberitahukan alamat tempat kerja, tempat kuliah dan tempat tinggal korban.

Tribunnews.com harus lebih meningkatkan lagi kekonsistenannya dalam menyajikan pemberitaan yang responsif. Jurnalis hendaknya berhati-hati dan bijaksana dalam pembuatan pemberitaan kejahatan susila agar bisa terhindar dari pelanggaran kode etik jurnalistik dan berperan dalam mencegah terulangnya kejahatan susila. Dewan Pers juga harus memberikan sanksi bagi 
jurnalis yang melanggar Kode Etik Jurnalistik agar profesionalitas dan kualitas pemberitaan tetap terjaga. Karena pemberitaan tidak hanya memberikan informasi namun juga memberikan dampak bagi masyarakat, khususnya dalam penelitian ini adalah korban dan keluarga korban.

\section{DAFTAR REFERENSI}

AJI, A. J. I. (2015). INDIKATOR SENSITIF GENDER UNTUK MEDIA Kerangka Indikator Mengukur Sensitivitas Gender pada Organisasi dan Konten Media (A. Grizzle (ed.)). Aliansi Jurnalis Independen (AJI) Indonesia.

Aristi, N., Janitra, P. A., \& Prihandini, P. (2021). Fokus narasi kekerasan seksual pada portal berita daring selama pandemi COVID-19. Jurnal Kajian Komunikasi, 9(1),. https://doi.org/10.24198/jkk.v9i1.30673

Arnus, S. H. (2014). INDUSTRIALISASI MEDIA MASSA DAN ETIKA JURNALISTIK. Al-Mun₹ir, 7(2). https://core.ac.uk/download/pdf/231139193.pdf

Berg dan Lune. (2012). Qualitative Research Methods for the Social Sciences. Pearson Education, Inc.

Choliq, A. D. (1970). HUKUM, PROFESI JURNALISTIK DAN ETIKA MEDIA MASSA. Jurnal Hukum, 25(1). https://doi.org/10.26532/jh.v25i1.200

Gaio, A. M. S. (2015). ANALISIS FRAMING ROBERT ENTMAN PADA PEMBERITAAN KONFLIK KPK VS POLRI DI VIVANEWS.CO.ID DAN DETIKNEWS.COM. JISIP : Jurnal Ilmu Sosial Dan Imu Politik, 4(3). https://doi.org/https://doi.org/10.33366/jisip.v4i3.126

Ghofur, A., \& Rachma, E. A. (2019). Pemanfaatan Media Digital Terhadap Indeks Minat Baca Masyarakat Kabupaten Lamongan. Gulawentah:Jurnal Studi Sosial, 4(2). https://doi.org/10.25273/gulawentah.v4i2.5524

Handoyo, P. (2016). Representasi Perempuan dalam Media No Title. SEMINAR NASIONAL GENDER \& BUDAYA MADURA III MADURA: PEREMPUAN, BUDAYA \& PERUBAHAN, 137142. https://lppm.trunojoyo.ac.id/budayamadura/wpcontent/uploads/2016/10/2-20.-ARTIKEL.pdf 
Indainanto, Y. I. (2020). Normalisasi Kekerasan Seksual Wanita di Media

Online. Jurnal Komunikasi, 14(2).

https://doi.org/10.21107/ilkom.v14i2.6806

Nuzuli, A. K. (2021). Pelatihan Media Sensitif Gender bagi Penggiat Media Bersama DP3AP2KB Provinsi Jawa Tengah. Jurnal Komunikasi Profesional, 5(3).

https://doi.org/https://doi.org/10.25139/jkp.v5i3.3815

Nuzuli, A. K., Natalia, W. K., \& Adiyanto, W. (2021). Tinjauan Pelanggaran Kode Etik Jurnalistik dalam Pemberitaan Prostitusi Online di Surabaya. Jurnal Warta ISKI, 4(1).

https://doi.org/https://doi.org/10.25008/wartaiski.v4i1.108

Rossy, A. E., \& Wahid, U. (2015). Analisi Isi Kekerasan Seksual Dalam

Pemberitaan Media Online Detik.Com. Jumal Komunikasi, 7(2). https://doi.org/10.24912/jk.v7i2.15

Sugiyono. (2018). Metode Penelitian Kuantitatif,Kualitatif dan R\&D. In ke26. PT Alfabet.

Wahyudiyono. (2019). Implikasi Penggunaan Internet Terhadap Partisipasi Sosial di Jawa Timur. Jurnal Komunika: Jurnal Komunikasi, Media Dan Informatika, 8(2). https://doi.org/DOI:

10.31504/komunika.v8i2.2487 